\title{
СТОМАТОЛОГИЧЕСКИЕ ПРОЯВЛЕНИЯ У ПАЦИЕНТОВ, СТРАДАЮЩИХ ГАСТРОЭЗОФАГИАЛЬНОЙ РЕФЛЮКСНОЙ БОЛЕЗНЬЮ
}

\section{DENTAL MANIFESTATIONS IN PATIENTS WITH GASTROESOPHAGIAL REFLUX DISEASE}

\section{Zhurbenko \\ A. Marinkina}

Summary. Various diseases of organs and organ systems can affect not only the entire body, but also the patient's dental health. In the modern world, the number of men and women with chronic diseases, including those with gastroesophageal reflux disease, is growing every year, regardless of age. This pathology can manifest itself as esophageal and extraesophageal symptoms. A large group of extraesophageal symptoms are manifestations of the disease in the oral cavity - dental symptoms. In this regard, the dentist needs to correctly recognize and differentiate the disease. When working with patients with chronic diseases, it is important that the dentist and the patient's doctor work together to improve the results of complex treatment.

Keywords: dental manifestations, gastroesophageal reflux disease, oral diseases, hygiene.

\section{Вве $е$ ение}

B настоящее время, современный человек встречается с рядом трудностей - стресс, плохая экология, уменьшение физической нагрузки, вредные привычки. Все эти факторы влияют на внутреннее и внешнее состояние организма, и являются основными пунктами в развитии заболеваний со стороны различных систем органов.

Звеньями развития заболеваний желудочно-кишечного тракта, помимо вышеперечисленных факторов, является несбалансированное и нерациональное питание, несвоевременность приема пищи, частые перекуcы.

Рост пациентов с заболеваниями желудочно-кишечного тракта увеличивается с каждым годом. Распространенность данных заболеваний достигает 70\% населения Российской Федерации [2,8,14]. Наиболее часто, встречаются пациенты с гастроэзофагиальной
Журбенко Вероника Александровна

ФГБОУ ВО «Курский Государственный Медичинский Университет» Минздрава России prepvermed@mail.ru

Маринкина Анастасия Андреевна

ФГБОУ ВО «Курский Государственный Медичинский Университет» Минздрава России

Аннотация. Различные заболевания органов и систем органов могут отражаться не только на весь организм, но и на стоматологическом здоровье пациента. В современном мире, число мужчин и женщин с хроническими заболеваниями, в том числе и с гастроэзофагеальной рефлюксной болезнью, растет с каждым годом, вне зависимости от возраста. Текущая патология может проявляться как пищеводными, так и внепищеводными симптомами. Большую группу внепищеводных симптомов составляют проявления болезни в полости рта — стоматологические симптомы. В связи с этим, врачу-стоматологу необходимо правильно распознавать и дифференцировать заболевание.

Ключевые слова: стоматологические проявления, гастроэзофагиальная рефлюксная болезнь, заболевания полости рта, гигиена.

рефлюксной болезнью, гастритом, а также язвенной болезнью желудка и двенадцатиперстной кишки $[1,12,15]$.

Гастроэзофагиальная рефлюксная болезнь - это хроническое заболевание, рецидивирующего характера, которое обусловлено нарушением моторной и эвакуаторной функции и характеризующееся спонтанным, регулярно повторяющимся забросом в пищевод содержимого желудка с формированием характерных клинических симптомов [3].

Современные исследования свидетельствуют о высокой частоте поражения полости рта при наличии гастроэзофагиальной рефлюксной болезни $[6,9,10]$.

Наличие соматических заболеваний у пациента, в том числе и заболеваний желудочно-кишечного-тракта, в большинстве случаев, отражается на стоматологическом здоровье и имеет свои симптомы, поэтому при достаточной высокой распространенности заболеваний данной группы, врачу-стоматологу необходимо 
Таблица 1. Значения индекса интенсивности кариеса зубов

\begin{tabular}{|l|l|}
\hline $\begin{array}{l}\text { Величина интенсивности } \\
\text { кариеса }\end{array}$ & $\begin{array}{l}\text { Значения интенсивности } \\
\text { кариеса }\end{array}$ \\
\hline Менее 1,5 & Очень низкая \\
\hline $1,6-6,2$ & Низкая \\
\hline $6,3-12,7$ & Умеренная \\
\hline $12,8-16,2$ & Высокая \\
\hline Более 16,3 & Очень высокая \\
\hline
\end{tabular}

Таблица 2. Значения индекса Грина-Вермиллиона

\begin{tabular}{|l|l|}
\hline 3начение упрощенного индекса гигиены полости рта & Уровень гигиены \\
\hline $0-1,2$ & хороший \\
\hline $3,3-3,0$ & удовлетворительный \\
\hline
\end{tabular}

Таблица 3. Значения пародонтального индекса

\begin{tabular}{|l|l|}
\hline Балльная система & Значение индекса \\
\hline $0,1-1,5$ балла & Начальная и легкая степень патологии пародонта \\
\hline $1,5-4,0$ балла & Средняя степень патологии пародонта \\
\hline $4,0-8,0$ & Тяжелая степень патологии пародонта \\
\hline
\end{tabular}

знать и владеть знаниями о проявлениях конкретных заболеваний со стороны полости рта.

\section{Шель исслеАования}

Целью данного исследования является изучение и регистрация изменений в ротовой полости у пациентов, страдающих гастроэзофагиальной рефлюксной болезнью.

\section{Материалы и метолы}

Для реализации поставленной цели было осмотрено 35 пациентов в возрасте от 30 до 60 лет. Обследуемые пациенты были разделены на 3 группы в зависимости от возраста. Первая группа включала пациентов в возрасте от 30 до 40 лет; вторая группа - от 40 до 50 лет; третья группа - от 50 до 60 лет. В анамнезе данных больных отмечалось наличие гастроэзофагеальной рефлюксной болезни.

Последовательность обследования заключалась в определении индекса КПУ, упрощенного индекса гигиены полости рта, пародонтального индекса PI, а также $\mathrm{pH}$ слюны.

Интенсивность кариеса среди населения рассчитывается при помощи индекса КПУ, где К - сумма зу- бов, подверженные кариесу, П - сумма пломбированных зубов, У - сумма зубов, которые подверглись хирургическому удалению у одного пациента. Оценка результатов исследования с помощью индекса КПУ определялась по группам интенсивности. Значения интенсивности кариеса рассмотрены в таблице 1 [13].

Уровень качества гигиены полости рта исследуют с помощью индекса Грина - Вермиллиона, который позволяет оценить наличие зубных отложений. Анализ результатов, полученных при использовании индекса, проводят визуально, либо с помощью специального раствора Шиллера - Писарева. Во время проведения данного индекса необходимо использовать вестибулярные поверхности 16,11,26,31 зубов и язычные поверхности 36 и 46 зуба. Интерпретируют индекс в соответствии со значениями в таблице 2 [5].

Состояние тканей пародонта у пациентов, с наличием заболеваний желудочно-кишечного тракта, определяли по пародонтальному индексу РІ. Пародонтальную оценку проводили по балльной шкале, которая указана в таблице 3 [14].

Важное значение при определении стоматологической патологии у лиц, страдающих гастроэзофагеальной рефлюксной болезни, является определение $\mathrm{pH}$ смешанной слюны для клинико-лабораторного анали- 
за $[5,14]$. Для этого исследования необходимо собрать слюну натощак или после приема пищи через 2 часа в общем количестве 1 мл. После этого, специализированную индикаторную бумагу опускали в биологический материал на 5 секунд, затем извлекали и сравнивали с рН-шкалой [14].

\section{Результаты исслеАования \\ и обсу жАения}

Среди осмотренных пациентов, количество женщин составило 23 человека, а мужчин 12 человек, 65,7\% и $34,3 \%$ соответственно.

Анализируя результаты определения индекса КПУ, было выявлено, что интенсивность кариеса в трех возрастных группах увеличивается, в прямой зависимости от возраста. Данные значения индекса составляют в первой группе - 9,8 2,91, что соответствует умеренной интенсивности. Уровень интенсивности кариеса

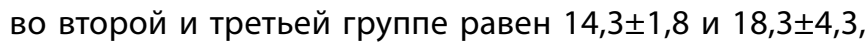
что равнозначно высокой и очень высокой интенсивности кариеса.

Рассматривая результаты, можно сказать, что со стороны твердых тканей зубов, отмечается множественный кариес. При стоматологическом осмотре, во всех возрастных группах, пациенты страдают эрозиями твердых тканей зубов. Упомянутая выше патология развивается вследствие воздействия кислого содержимого на эмаль зубов [7].

Величина пародонтального индекса в возрасте

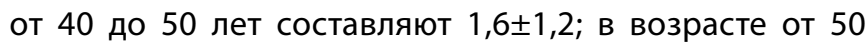

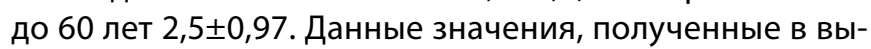
шеперечисленных возрастных группах, совпадают с интервальными значениями средней степени патологии пародонта. Показателем легкой степени патологии пародонта является значение индекса в группе обследуе-

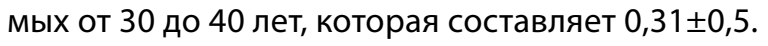

Во время стоматологического осмотра у пациентов (40\%) выявлена гиперемия и отечность десны, определяется боль и кровоточивость во время чистки зубов.

Вышеприведенные признаки служат ухудшающем маркером индивидуальной гигиены полости рта, что может привести к образованию наддесневых и поддесневых зубных отложений.

Средний показатель индекса гигиены полости рта у пациентов первой и второй группы удовлетворитель-

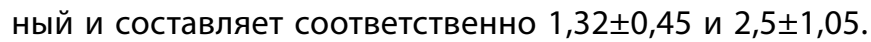
В третьей возрастной группе значение OHI-S индекса равно $4,3 \pm 1,08$, что определяет плохую гигиену поло- сти рта. Во всех обследуемых группах, у пациентов зарегистрированы наличие твердых и мягких зубных отложений.

При наличии соматической патологии необходимо тщательно уделять внимание индивидуальной гигиене полости рта. Использовать в своем рационе не только основные средства для гигиены полости рта, но и дополнительные [16]. При выборе зубной пасты следует выбирать противовоспалительные зубные пасты, так как при текущем заболевании возрастает риск развития заболеваний пародонта и возникновения гиперестезии. Рекомендуют применять зубную щетку мягкой и средней жесткости. Используя во время чистки зубов зубную нить, данное средство эффективно очищает от остатков пищи и зубного налета контактные поверхности зубов, что минимизирует развитие кариеса в данной области. Незаменимым средством при уходе за полостью рта при наличии соматической патологии является ирригатор. Мощный водный поток ирригатора вымывает остатки пищи и очищает поверхности зуба, а также, благодаря напору воды, массажирует десна, улучшая кровоснабжение. Из жидких средств для гигиены полости рта, при гастроэзофагеальной рефлюксной болезни, можно применять ополаскиватели. Пациент, в зависимости от ситуации в полости рта, может сам корректировать выбор ополаскивателей - противокариозные или противовоспалительные средства $[5,15,16]$.

При рассмотрении результатов на рН-исследование слюны у пациентов с патологией желудочно-кишечного тракта была выявлена кислая среда у всех групп обследуемых (100\%). Сдвиг рН ротовой полости в сторону кислого является причиной развития не только множественного кариеса, но и генерализованной повышенной чувствительности твердых тканей зубов [7].

При осмотре пациентов, имеющих гастроэзофагеальную рефлюксную болезнь, выявляются также изменения со стороны слизистой оболочки полости рта. В большинстве случаев, пациенты предъявляют жалобы на чувство жжения в ротовой полости, привкус кислого содержимого во рту, а также на наличие неприятного запаха в полости рта. Все эти симптомы указывают на начальное проявление болезни $[1,4,6,11]$.

У большей половины обследуемых (53\%) выявлены жалобы на сухость в полости рта. Данный симптом является одним из распространенных стоматологических признаков наличия гастроэзофагеальной рефлюксной болезни у пациентов $[1,4]$.

Объективно, у пациентов, во всех возрастных категориях, отмечаются поражения со стороны языка. Так, при стоматологическом осмотре выявлена отечность 
языка, атрофический глоссит и наличие налета на поверхности языка.

\section{ВывО $\triangle \mathrm{b}$}

Настоящее исследование показало, что уровень стоматологической патологии у пациентов с гастро- эзофагиальной рефлюксной болезнью весьма высок и требует правильного подхода к лечению заболевания и тщательного ухода за полостью рта. При работе с пациентами, имеющих хронические заболевания, важна совместная работа врача-стоматолога и лечащего врача пациента для улучшения результатов комплексного лечения.

\section{ЛИТЕРАТУРА}

1. Арахова, 3.А. Состояние полости рта при заболеваниях желудочно-кишечного тракта у детей / 3.А. Арахова, М.С. Трухманов // Университетский терапевтический журнал. - 2020.-Т.2.-№ 3.-С.64-74.

2. Бавыкина, Т.Ю. Полость рта - зеркало заболеваний внутренних органов / Т.Ю. Бавыкина, 0.А. Ефремова // Научные ведомости Белгородского государственного университета. Серия: Медицина. Фармация. — 2011. — № 10.— С. 236-238.

3. Внепищеводные проявления гастроэзофагеальной рефлюксной болезни: фокус на стоматологические симптомы / Р.А. Айвазова, Е.Н. Поликанова, А.А. Самсонов [и др.] // Фарматека.— 2017.— № 13(346).— - . 48-52.

4. Джамалдинова, Т.Д. Проявления гастроэзофагеальной рефлюксной болезни в полости рта / Т.Д. Джамалдинова, Л.Н. Максимовская, Е.Д. Ли // Экспериментальная и клиническая гастроэнтерология.— 2010.— № 9.—С. 23-27. (гастро 9)

5. Килафян, 0.А. Гигиена полости рта: краткий курс / 0.А. Килафян.— Ростов н/Д: Феникс.—2014 — С. 122-132.

6. Назарян, Р.С. Внутриротовые проявления гастроэзофагальнорефлюксной болезни у детей / Р.С. Назарян, Е.В. Карнаух // Научные ведомости Белгородского государственного университета. Серия: Медицина. Фармация. — 2011. — № 22(117). — С. 244-248.

7. Нарушения кислотно - основного равновесия в полости рта при общесоматической патологии / В.А. Румянцев, Л.К. Есаян, Е.Д. Зюзбкова [и др.] // Стоматология.-2013. - № 2. С. 22-26.

8. 0 взаимосвязи гастроэзофагеально рефлюксной болезни и гальваноза в полости рта / Т.С. Чемикосова, С.А. Лазарев, А.А. Голубь, 3.Ф. Ситдикова // Исторические вехи развития стоматологической службы Республики Башкортостан: Сборник научных трудов, посвященный 100-летнему юбилею со дня образования Республики Башкортостан, Уфа, 11-12 апреля 2019 года. - Уфа: Башкирский государственный медицинский университет, 2019. - C. 270-273.

9. Робакидзе, Н.С. Патогенетические аспекты поражения полости рта при воспалительных заболеваниях кишечника / Н.С. Робакидзе, 0.Б. Щукина // Российский журнал гастроэнтерологии, гепатологии, колопроктологии. - 2019. - Т. 29. — № 4. — C. 15-21.

10. Рысбаева, Ж.И. Микрофлора полости рта у детей с заболеваниями ЖКТ / Ж.И. Рысбаева, Г.А. Каркимбаева, Г.Т. Ермуханова // Вестник Казахского национального медицинского университета. - 2017. — № 2.— С. 130-133.

11. Сазанская, Л.С. Исследование микрофлоры полости рта у мужчин и женщин с гастроэзофагеальной рефлюксной болезнью / Л.С. Сазанская, М.М. Гулуа // Chronos: естественные и технические науки. — 2019.— № 2(24).—C. 46.

12. Скачко, Б.Г. Болезни органов пищеварения / Б.Г. Скачко. - М.: Мир и образование, 2013. - 288с.

13. Современные системы оценки и регистрации кариеса зубов. 0бзор литературы / М.Ю. Пастбин, М.А. Горбатова, Е.И. Уткина [и др.] // Экология человека.— 2013.— № 9.- С. 49-55.

14. Стоматологический статус пациентов с гастроэзофагеальной рефлюксной болезнью в зависимости от приема ингибиторов протонной помпы / Л.С. Сазанская, М.М. Гулуа, Э.М. Гильмияров, Э.Г. Маргарян // Стоматология. — 2020. - Т. 99. - № 5. — С. 25-31.

15. Терапевтическая стоматология: учебник в 3 ч./ под ред. Г.М. Барера. - 2-е изд., доп. и перераб. - М.: ГЭОТАР,2015.— Ч. 3. - Заболевания слизистой оболочки полости рта.-С. 153-161.

16. Флейшер, Г.М. Гигиена полости рта. Монография / Г.М. Флейшер // Стоматология. — 2018.

( Ж Журбенко Вероника Александровна ( prepvermed@mail.ru ), Маринкина Анастасия Андреевна. Журнал «Современная наука: актуальные проблемы теории и практики» 